\title{
Comparative Analysis of Competitive Strategy Implementation
}

\author{
Maina A. S. Waweru \\ University of Nairobi, Kenya. \\ United States International University, Kenya. \\ P.O. BOX 40969, GPO 00100, Nairobi, Kenya \\ Tel: +254-206-968-201, +254-733-610-086Ｅ-mail: mas.waweru@dayliff.com
}

Received: June 16, 2011 Accepted: August 7, 2011 doi:10.5430/jms.v2n3p49

\begin{abstract}
This paper presents research findings on Competitive Strategy Implementation which compared the levels of strategy implementation achieved by different generic strategy groups, comprising firms inclined towards low cost leadership, differentiation or dual strategic advantage. The study sought to determine the preferences for use of implementation armaments and compared how such armaments related to the level of implementation achieved. Respondents comprised 71 top executives from 59 companies among the top 300 private sector firms in Kenya. SPSS software was used to conduct t-test, ANOVA, and multiple linear regression analysis, to within $95 \%$ confidence interval or $5 \%$ statistical significance. The results indicated that there was no significant difference between the levels of strategy implementation achieved by any pair set of the three strategic groups. The study revealed that the predictors of strategy implementation include the firm's capacity to overcome resistance to change, having incentives based on meeting strictly quantitative targets, adopting a win-lose competitive posture, its effectiveness in strategy implementation, and the environmental rate of change. The results also indicated that there was no significant difference between the preferences for use of either win-lose or win-win competition by any pair set of the strategic groups.
\end{abstract}

Keywords: Competitive Strategy, Generic Strategy, Strategy Implementation, Implementation Predictors

\section{Introduction}

The goal of every competitive strategy is to achieve sustainable competitive advantage (Coyne, 1986; Stalk \& Lachenauer, 2004). This objective is achieved through competitive strategy implementation, which is defined primarily by the strategic advantage of either low cost leadership or differentiation (Porter, 1998a). The transient nature of some competitive advantages over the changing environmental conditions require that strategists deeply understand the competition process and the factors that underlie each advantage in order to attune themselves to changes in such underlying conditions (Christensen, 2001). Such changes, which are at times turbulent and unpredictable, have made competitiveness become a central preoccupation of both advanced and developing countries (Porter, 2003).

The success or failure of strategies is linked, to a great measure to how they are implemented (Argyris, 1989; Gluck, Kaufman, \& Walleck, 1980; Hambrick \& Canella, 1989; Kazanjian \& Drazin, 1987; Reed \& Buckley, 1991; Stalk \& Lachenauer, 2004). Poor implementation can make sound strategic decisions ineffective, while successful implementation can make a doubtful strategic choice successful (Mintzberg, Quinn, \& Ghoshal, 2003; Andrews, 1980). However, implementation of strategy exhibits its own resistance which can invalidate the planning effort (Ansoff and McDonnell, 1990).

\subsection{Research Problem}

Firms have not been short of strategies but have fallen short of strategy implementation (Alexander, 1985; Brinkerhoff, 1996; Charan \& Colvin, 1999; Gluck et al., 1980; Kazanjian \& Drazin, 1987; Weiss \& Birnbaum, 1989). It is estimate that $70 \%$ of chief executive officers fail due to bad execution (Charan \& Colvin, 1999). Situations arise where the business environment is not conducive to business success, leading to aggressive competition for survival. Under such situations it is imperative that managers and scholars alike have ready access to empirically supported evidence that identifies the competitive strategy that may deliver comparatively superior performance in terms of the level of implementation achieved. This would therefore provide them the opportunity to posture the firm for success. Toward this end, the study sought to address this need and thereby contribute towards reducing the high failure rate in strategy implementation. 


\subsection{Synthesis and Hypotheses}

The criteria for competitive positioning are industry forces that compel the need for positioning (Porter, 1985, 1998a,). Porter's five forces model constitutes a framework for environmental threats and opportunities profile tool as it focuses on these two dimensions of strategic analysis. These forces may be summarized as emanating primarily from three areas comprising customers, suppliers and competitors. In addressing these five forces, and in order to effectively compete, firms must choose and adopt appropriate generic strategies. Such strategies are core ideas about how a firm can best compete in the market place. Porter's (1998a) generic strategies' model comprises two dimensions. The first is the strategic target or competitive scope, which indicates how widely the product is intended to compete, either throughout the industry or within a particular market niche. The second dimension is the strategic advantage or competitive advantage. This indicates the basis on which the product is intended to compete, either by uniqueness / differentiation as perceived by the customer, or low unit cost of production.

Porter (1985) identifies firms that practice both cost leadership and differentiation strategies simultaneously as being stuck in the middle. Johnson and Scholes (2002) critique Porter's differentiation concept by introducing the possibility of pursuing differentiation while maintaining low cost positioning. Two schools of thought have emerged from this discussion, with one supporting mutual exclusion of the two strategies (Dess \& Davis, 1984), while the other advocates simultaneous application of the two strategies (Certo \& Peter, 1995; Wright, Kroll, Tu, \& Helms, 1991). From this stand point, a question arises whether firms that are inclined to apply one school of thought achieve higher implementation than those that apply the other school of thought. Hence, the following null hypothesis H1.

H1 - There is no significant difference between the levels of implementation achieved by any pair set of strategic groups from among low cost leaders, differentiators and users of dual strategic advantage.

The importance of strategy implementation is underscored by its repeated mentions either explicitly or implicitly in the various definitions of strategic management by different scholars (Andrews, 1980; Ansoff, 1987; Certo \& Peter, 1995; Johnson \& Scholes, 2002; Pearce \& Robinson, 2005). Despite this significant mention, emphasis of its importance, tools of its facilitation and its challenges appear not to have been adequately addressed in literature. This situation has led to failed plans and abandoned planning efforts (Brinkerhorr, 1996; Gluck et al., 1980; Gottschalk, 1999; Hambrick \& Cannella, 1989; Kazanjian \& Drazin, 1987; Weiss \& Birnbaum, 1989). It may appear imperative therefore, that implementation is the nourishment and stimulant for the sustenance of strategic management and it is at the heart of the discipline.

The essence of implementation is to create a reorientation in the organisational status to align it with the planned strategic decision. This reorientation is in itself a change, which elicits resistance. Resistance to change occurs whenever an organisational change introduces a discontinuous departure from the historical behaviour, culture, and power structure (Ansoff \& McDonnell, 1990). This identifies the threshold of the implementation challenge, for which a model is shown in figure 1 . The need to implement a new strategy requires the installation of new capabilities (preparedness, Pc) to support the strategy in order to realise the intended objectives which would appear to be measured by the level of implementation achieved (Li). The capability installation may in turn require changes in culture, management orientation and power structures, thereby inducing greater resistance to change (Rc) that compounds the implementation of the new strategy. Such resistance is manifested in behavioural ( $\mathrm{Br}$ ) and systemic ( $\mathrm{Sr}$ ) resistances to change (Ansoff \& McDonnell, 1990), and the success of the implementation initiative would appear to be dependent on how effective these resistances are overcome $(\mathrm{Cr})$ within a continuously changing environment (Ec). It would appear therefore that the implementation process effectiveness $(\mathrm{Ce})$ is a predictor of the implementation level achieved. From the analogue model it would appear that if the firm's capacity to overcome resistance to change is Cr1, it would results in Li1 as the level of implementation achieved, while Cr2 would lead to Li2. Thus, the null hypothesis H2 proposed as follows.

H2 - The implementation level achievable can be predicted by the firm's capacity to overcome resistance to change, its preparedness for strategy implementation, its effectiveness in strategy implementation, the environmental rate of change, and the time taken to implement new strategies.

\section{$<$ Figure 1 about here>}

The implementation challenge emanates from lack of capacity to deal with the broad social, political, cultural and organisational dimensions, which interact in complex and completely unpredictable ways whenever new strategies are to be adopted. These may compel changes in individual or organisational roles, create severe institutional constraints, and new interaction patterns with other players in the industry (Brinkerhoff, 1996). Hence, the implementation challenge of realising the intended strategy in the face of opposing forces or resistance. Strategy implementation therefore becomes 
essentially a management of change issue with its resultant resistance. It is noted that the model in Figure 1 provides a view that the maximum level of implementation that can be achieved as infinity, as there is always a chance of improvement using the continuous improvement principle of Total Quality Management, (Ross, 1999).

Literature contends that for successful strategy implementation, there is need to create a strategic fit between the soft and hard implementation armaments and the organizational strategic variables (Ansoff \& McDonnell, 1991; Argyris, 1989; Brodwin \& Bourgeois, 1984; Hussey, 1996; Skivington \& Daft, 1991; Stalk \& Lachenauer, 2004). The soft elements comprise the behavioural dimensions while the hard elements comprise the analytical or technical dimensions to the process of strategic decision-making and the subsequent implementation of strategy. From this perspective the following null hypothesis $\mathrm{H} 3$ was proposed.

H3 - There is no significant difference between the preference for use of soft and hard implementation armaments by any pair set of strategic group from among low cost leaders, differentiators and dual advantage strategists.

Among the strategy implementation approaches are win-win and win-lose competition, for which there is contention over the one to adopt. Supporters of the former argue that it is important to appreciate the uniqueness and resourcefulness of the competition and their success formula (Jarillo \& Stevenson, 1991; Nielsen, 1987; Zahra \& Chaples, 1993). In addition, it is necessary to understand how to use competitive pressure to create an optimum combination of competition and cooperation among selected rivals, and hence allow competition to co-exist with cooperation especially for firms within business clusters (Brandenburger \& Nalebuff, 1996; D’Aveni, 2002; Nielsen, 1987; Porter, 1998b). Supporters of the latter call for firms to focus relentlessly on competitive advantage, and aim at crushing competition (Poage, 2004; Stalk \& Lachenauer, 2004). This led to the proposal of the following null hypotheses, $\mathrm{H} 4$ and $\mathrm{H} 5$. .

H4 - There is no significant difference between the preferences for use of win-lose competition by any pair set of strategic group from among low cost leaders, differentiators and dual advantage strategists.

H5 - There is no significant difference between the preferences for use of win-win competition by any pair set of strategic group from among low cost leaders, differentiators and dual advantage strategists.

\section{Research Design}

\subsection{Research Setting}

The private sector has become the central focus for economic development in African countries in recent years primarily due to the failure of public sector-led economic development and the rise in globalisation (United Nations Industrial Development Organization, 1999). The latter has caused increased competition in markets around the world. The increased relative importance of the private sector in Sub-Saharan Africa is attributable to a sharp drop in public sector investment rather than any substantial growth in private sector investment itself (UNIDO, 1999).

The research data was collected from the Republic of Kenya during a time of slow economic recovery in mid 2007. The business environment in 2002 to 2006 was not conducive to business success, with CEOs in East Africa citing competition as the third most pressing challenge (after infrastructure) to businesses throughout the region (Eastern Africa Association, 2006; Kenya Government, 2006; Pricewaterhouse Coopers \& Nation Media Group, 2006). The Kenya Government acknowledged the indispensable role of the private sector as a major prime mover for long term and sustainable economic growth (Kenya Government, 1988, 1997, 2003, 2006). Kenya had a resourceful and resilient private sector (Eastern Africa Association, 2006) that accounted for approximately $80 \%$ of Gross Domestic Product. Large private sector firms were estimated to be 1,000 and contributed $30 \%$ of GDP.

The study used triangulation at the philosophical level of research, while the practical level involved both quantitative and qualitative research methods. The sample frame comprised the top 300 private firms in Kenya, based on their remittances of value added tax to the government during the period 2002 to 2005 . The participating firms had a minimum annual turnover of about US\$6.1 million, and having been established for at least seven years prior to the survey. Pre-test and the survey was done using a structured questionnaire comprising closed and open ended questions. These were was administered in all major cities using e-mail and follow-up telephone or face to face interviews. Questionnaires were sent to top executives of 170 companies selected using simple random sampling, cutting across all industry sectors and business segments. Questions were posed to respondents that led to identification of their strategic groups, the armaments they used in implementation, their level of achievement in strategy implementation, and the competitive approaches that they adopted. 


\subsection{Measurement}

Strategy and implementation process variables were measured by using 5-point Likert scale indicating degree of agreement to statements operationalized to reflect the intended variable. Strategy variables included low cost leadership, differentiation and a combination of low cost and differentiation otherwise referred to as dual strategic advantage. Membership to a strategic group was measured by the firms' possession of skills and organisational requirements for fostering the specific generic strategy. Such resources included cost cutting measures to avoid non-value adding activities, continuous improvement and benchmarking orientation, incentives based on meeting strict quantitative targets, capability for basic research, corporate reputation for quality and technical leadership, and attracting highly skilled labour and creative people. Implementation variables included resources, structure, leadership, rewards, consensus type, consensus building, training, culture, communication, resistance to change, competitive modes of win-lose and win-win. These variables have been used by other researchers in similar areas of study including Dess and Davis (1984), Furrer et al. (2002), Govindarajan (1988), Gupta (1987), Skivington and Daft (1991), and Wright et al. (1991). Implementation process variables included preparedness, effectiveness, environmental rate of change, time, capacity to overcome resistance to change, and the level of implementation achieved as shown in Figure 1.

\subsubsection{Validity Tests}

The instrument was pre-tested for face and construct validity, by linking it to background theory and asking a panel of experts to present their opinions on its suitability for the research. Indeed Emory (1985) and Cooper and Schindler (2008) contend that content validity is judgemental. In addition, the split half method was used with Spearman Brown prophesy formula applied to adjust the correlation coefficient for reliability.

\subsection{Analytical Methods}

As in previous research in this area, correlation analysis, multiple linear regression, and analysis of variance (ANOVA) were used to determine the extent to which strategy implementation was related to generic strategies, in addition to use of t-tests for tests of hypotheses (Aosa, 1992; Jennings \& Seaman, 1994; Porter, 2003; Skivington \& Daft, 1991; Tan \& Litschert, 1994; Wright et al., 1991). The hypotheses were tested within $95 \%$ level of confidence interval or $5 \%$ level of significance.

\section{Data Analysis and Results}

Seventy one responses were received from 59 companies, this comprising $42 \%$ response rate from the target 170 respondent firms. The respondents were drawn from the firms' top management teams comprising CEOs 25\%, general managers 54\% and SBU managers 21\%. The majority of respondents $76 \%$ had served their respective firms for a period of more than four years, $61 \%$ of whom had served for 4 to 16 years. A majority of $82 \%$ firms had been established for over 20 years, while all the participating firms were drawn from across all industry sectors.

The study identified three strategic groups comprising low cost leaders $11 \%$, differentiators $31 \%$ and those that adopted combined cost leadership and differentiation strategies or dual strategists 58\%. An examination of the cumulative percentage responses showing agreement and strong agreement, to the statements that there was serious consideration and availability of soft implementation armaments within firms, showed the following pattern. Staff training and communication had the highest score of about $92 \%$ and $90 \%$ respectively. This was followed by corporate culture which had a score of about $85 \%$, closely followed by leadership with about 82\%. In contrast, it appeared that firms were performing comparatively poorly with consensus building and their ability to overcome resistance to change, both having a score of $66 \%$. With regard to hard implementation armaments, organizational resources had a response of $92 \%$, organisational structure with $76 \%$, and reward systems $66 \%$. Others included win-win competition which had a response rate of $64 \%$ and finally win-lose competition with a low rate of $34 \%$. From these results it would appear that firms give great emphasis to provision of implementation resources with declining importance accorded to organisational structure, reward systems and competitive posture. However, the analyses also showed that win-lose competition was given less emphasis and firms were more inclined to practice coopetition rather than competition.

The results showed that a cumulative majority of $70 \%$ of the firms concurred that they had high preparedness level when implementing new strategies. A similar majority of 51\% indicated general agreement to the fact that their firms experienced low resistance to change when implementing new strategies. $65 \%$ cumulative majority of the firms indicated disagreement to the fact that the average rate of environmental change in their business was very slow or rather stable. This implied that the group experienced an average rate of change in the business environment that was neither very slow nor stable. A majority of $43 \%$ of the firms expressed general disagreement to the statement that the time taken to complete implementation of new strategies was very short. This group implied that the implementation efficiency was not comparatively very high. The high effectiveness shown for strategy implementation by the 
cumulative majority of $81 \%$ firms implied that most strategy projects were fulfilled despite some taking comparatively longer to complete than expected. A cumulative majority of about $75 \%$ of the firms indicated that the level of strategy implementation achieved in their firms was very high. The results indicated most favourable conditions for strategy implementation within the firms, despite the recorded challenge of a dynamic business environment whose pace was greater than very slow or stable conditions.

To compare the three strategic groups, it was necessary to conduct three paired t-tests for each of hypotheses $1,3,4$ and

5. The results for tests of hypotheses 1 are shown in Tables 1 to 3.

$<$ Table 1 about here>

The results for the comparison of the implementation level achieved by low cost leaders and differentiators shown in Table 1 revealed that the Levene's test of equality of variances did not reach significance and therefore fail to reject the null hypothesis. In addition, the results were not significant and hence, there was no significant difference between the levels of implementation achieved by low cost leaders and differentiators.

$<$ Table 2 about here>

Table 2 provides the results for the comparison of low cost leaders and dual strategists, which met the condition for equal variance though they were not significant and therefore fail to reject the null hypothesis. Therefore, there is no significant difference between the levels of implementation achieved by low cost leaders and dual strategists.

\section{$<$ Table 3 about here>}

Table 3 shows the results for the comparison of differentiators and dual strategists, which reveal that they met the conditions for equal variance, though the results were not significant. Hence, fail to reject the null hypothesis H1.

In order to test hypothesis H2, multiple linear regression analysis was conducted using the stepwise method, for which the results are shown in Table 4. All the 23 implementation armaments, implementation process variables and skill and resources for promoting generic strategies identified above were included.

\section{$<$ Table 4 about here>}

In the model summary, model 5 had an unadjusted R square of 0.551 , which implied that $55 \%$ of the changes in value of implementation level achievable (Li) was explained by the firm's effectiveness in strategy implementation (Ce), its capacity to overcome resistance to change (Cr), incentives based on meeting strictly quantitative targets (Qt), win-lose competitive posture (Wl), and the environmental rate of change (Ec). In the ANOVA table, the p-value is 0.000 with F-value equal to 15.942, which means the overall model with five variables is significant. In addition, the individual significance levels of model 5 , shows that all variables, except the intercept were significant, with p-values ranging from 0.045 to 0.000 . Hence, the multiple regression model, using un-standardized Betas, can be stated as follows.

$$
L_{i}=.346 C_{e}+.353 C_{r}+.178 Q_{t}+.113 W_{l}+.131 E_{c}
$$

In checking for multicollinearity, it is noted that the variable inflation factors (VIF) for model 5 range between 1.035 and 1.478. These figures are far below the threshold of 10, beyond which collinearity or multicollinearity are a problem. This is also confirmed by the high tolerance shown to vary between .676 and .966 for the variables. The model therefore is free from the problem of multicollinearity. It is therefore noted that hypothesis $\mathrm{H} 2$ is supported except for the variables time and preparedness. In their place the variables $\left(Q_{t}\right)$ and $\left(W_{l}\right)$ were shown to be predictors.

Hypothesis H3 was tested using t-tests and the results are shown in Tables 5 to 7 . Results comparing low cost leaders and differentiators on soft implementation armaments as shown in Table 5 revealed that there was no significant difference between the use of leadership, training, consensus building, and organisational culture by low cost leaders and differentiators.

\section{$<$ Table 5 about here>}

In addition, low cost leaders and differentiators showed no significant difference in their use of communication, $\mathrm{t}(28)=$ -3.314, $\mathrm{p}<.05$, two-tailed, and capacity to overcome resistance to change, $\mathrm{t}(28)=-2.256, \mathrm{p}<.05$, two-tailed. From these results it can be concluded that there was no significant difference between cost leaders and differentiators in their preference for use of soft implementation armaments.

With regard to the use of hard implementation armaments, the results for all the variables met the condition for equality of variance, and therefore fail to reject the null hypothesis. Among these, the results for organizational structure and resources were significant and therefore report that there is no significant difference between low cost leaders and differentiators in the emphasis they gave to organizational structure, $t(28)=-3.210, p<.05$, two-tailed, and resources, $t$ 
(28) $=-2.568, \mathrm{p}<.05$, two-tailed. It can therefore be concluded that there was no significant difference between cost leaders and differentiators in their preference for use of hard implementation armaments. Putting the two findings together, it can be summarized that there was no significant difference between the preference for use of soft and hard implementation armaments by differentiators and low cost leaders.

Table 6 shows the results for low cost leaders and dual strategist and indicates that there was no significant difference between the preference for use of leadership, communication, training, consensus building, and organizational culture and the firms' capacity to overcome resistance to change by the two groups, with the last variable showing $t(47)=$ $-2.908, \mathrm{p}<.05$, two-tailed. These results show that there was no significant difference in the emphasis and availability of soft implementation armaments between low cost leaders and dual strategists.

$<$ Table 6 about here>

Results for hard implementation armaments as shown in Table 6 revealed that there was no significant difference between low cost leaders and dual strategists in how they considered and made available organisational resources, rewards, win-lose and win-win competitive postures. The same case applied to organisational structure, $\mathrm{t}(47)=$ -4.754, $\mathrm{p}<.001$, two-tailed. These results therefore show that there was no significant difference between low cost leaders and dual strategists in their use of hard implementation armaments. Considering the two findings on soft and hard armaments, it can be concluded that that there was no significant difference between low cost leaders and dual strategists in their use of soft and hard implementation armaments.

Comparison of differentiators and dual strategists are shown in Table 7 and the results revealed that there was no significant difference between the preferences for use of leadership, communication, training, culture and capacity to overcome resistance to change by these groups, including consensus building, t $(61)=2.087, \mathrm{p}<.05$, two-tailed. These results show that there was no significant difference between the preferences for use of soft implementation armaments by differentiators and dual strategists.

\section{$<$ Table 7 about here>}

The analyses of the hard implementation armaments showed that all variables met the condition for equal variance and hence, fail to reject the null hypothesis. The findings also showed that the results for all variables were not significant except for resources. It is therefore stated that there was no significant difference between the preferences for use of organisational structure, rewards, win-lose and win-win competitive postures by differentiators and dual strategists, as was the case for resources, $\mathrm{t}(61)=2.022, \mathrm{p}<.05$, two-tailed. Therefore, it is observed that there was no significant difference between these two groups in their preference for use of hard implementation armaments. The overall picture in these comparisons is that there was no significant difference between the preferences for use of soft and hard implementation armaments by differentiators and dual strategists.

Having reviewed the three strategic groups in different pairs, it is noted that they imply the need for failing to reject the null hypothesis H3. It is also noted that win-lose and win-win competitive postures are among hard implementation armaments and as demonstrated above for hypothesis H3, fail to reject the null hypotheses $\mathrm{H} 4$ and $\mathrm{H} 5$.

\section{Discussion and Conclusion}

All strategic groups appeared to be well endowed with strategy implementation armaments, and implementation process indicators. It would appear from the findings of $\mathrm{H} 1$ that irrespective of the strategic group one belonged to, the endowment with the requisite implementation armaments and process indicators assure a firm of success in strategy implementation.

From literature review, resistance to change and high rate of change in the business environment are stumbling blocks for effective strategy implementation. This shows that the findings are consistent with established body of knowledge to the extent that these two are predictors of the level of implementation achievable. Win-lose competition takes the perspective that you win or lose. Taking this position becomes a self-motivator for the competitors to ensure that they win, which implies success in strategy implementation and consequently survival for their businesses. This strong drive for success and hence, survival would explain the inclusion of this variable to predict the level of implementation achievable. On the other hand, a firm having incentives based on achieving quantitative targets has the ability to focus the implementers on measurable objectives. The awareness that the implementers will be rewarded based on the achievement of the set quantitative targets becomes a key motivator and hence, helps in the achievement of the intended strategy. This explains why this variable is also a predictor of the level of implementation achieved.

From the model in Figure 1, the preparedness in strategy implementation is equated to installing the necessary capabilities for the implementation of the new strategy. These capabilities include resources, among them time and 
human resources (creative staff), in addition to leadership. Others include capacity to overcome resistance to change, which is implemented through staff training and adopting appropriate consensus type together with encouraging consensus building in the firm. In addition, the firm provides appropriate reward systems that serve as incentives based on meeting strict qualitative targets. Finally, the firm requires instilling an approach for quality with continuous improvement and bench marking orientation. As will be noted in the equation 1, among these are predictors of the level of strategy implementation achievable. So, although preparedness as an independent variable does not appear to be a predictor, its components are predictors of the strategy implementation achievable.

All firms appeared well endowed with the necessary skills, resources and organizational requirements for fostering the strategies adopted, in addition to having the necessary implementation armaments. The findings on the use of these armaments seem to support the contention that for successful implementation of strategies, there is need to have a strategic fit between the soft and hard implementation armaments and the strategy being implemented (Ansoff \& McDonnell, 1991; Argyris, 1989; Brodwin \& Bourgeois, 1984; Hussey, 1996; Skivington \& Daft, 1991; Stalk \& Lachenauer, 2004). It would appear that irrespective of the strategy to be implemented, it is of paramount importance that there is available and in good measure, the requisite soft and hard implementation armaments in order to achieve high levels of success in implanting the strategy.

The study showed that there was no significant difference between the preferences for use of either win-lose or win-win competition by any pair set of strategic groups. This situation may explain the on-going discussion on which of these two to adopt. However, from strategy implementation perspective, the results showed that there is good reason to adopt win-lose competition as it is shown to be a predictor of the level of implementation achieved. This approach is a self motivator in that is it driven by the desire for survival. Coupled to having incentives based on achieving quantitative targets, this approach appears to become a stimulant in the achievement of strategy implementation. The study showed that the model in Figure 1 may be used to explain the implementation challenge, with emphasis on the identified predictors of implementation. In this regard, practitioners and scholars may be able to overcome the implementation challenge by instituting procedures and programs within their firms that give ample emphasis and priority to the identified predictors. Using this model and the mathematical model provided in the study, entrepreneurs, managers and scholars are better position to address the high organisational failures attributed to strategy implementation.

The study also revealed that firms are able to successfully use dual strategic advantage, without necessarily being 'stuck in the middle'. It therefore demonstrated a third strategic group, dual advantage strategists. By determining that non of the strategic groups achieved significantly higher strategy implementation than the others, the study revealed that practitioners may adopt a generic strategy of their choice that provides the best strategic fit to the firm's circumstances and desired competitive posture.

\section{References}

Alexander, Larry D. (1985). Successfully implementing strategic decisions. Long Range Planning, 18 (3), $91-97$. http://dx.doi.org/10.1016/0024-6301(85)90161-X

Andrews, Kenneth R. (1980). The concept of Corporate Strategy. Dow Jones-Irwin, Inc.

Ansoff, H Igor \& McDonnell, Edward J. (1990). Implanting Strategic Management. Prentice Hall Europe.

Ansoff, H Igor. (1987). The new Corporate Strategy management. Chapman \& Hall, London.

Aosa, Evans. (1992). An empirical investigation of aspects of strategy formulation and implementation within large, private manufacturing companies in Kenya (Unpublished doctoral dissertation). University of Strathclyde, Glasgow, Scotland.

Argyris, Chris. (1989). Strategy implementation: An experience in learning. Organizational Dynamics, 18 (2), 5-15. http://dx.doi.org/10.1016/0090-2616(89)90039-9

Brandenburger, Adam \& Nalebuff, Barry. (1996). Co-opetition. Doubleday, New York.

Brinkerhoff, Derrick W. (1996). Enhancing capacity for strategic management of policy implementation in developing countries [IPC Monograph No. 1]. United States Agency for International Development Project No. 936-5470.

Brodwin, David R \& Bourgeois, L T. (1984). Five steps to strategic action. California Management Review, 26 (3), 176-190.

Certo, Samwel C \& Peter, Paul J. (1995). The Strategic Management process. Chicago, Irwin. 
Charan, Ram \& Colvin, Geoffrey. (1999). Why CEOs Fail. Fortune, Vol.139, Issue 12, 68+. Retrieved from http://www.erikandanna.com/business/why_ceos_fail.htm

Christensen, Clayton M. (2001). The past and future of competitive advantage. MIT Sloan Management Review, 42 (2), 105-109. http://dx.doi.org/10.1126/science.1123633

Cooper, Donald R, \& Schindler, Pamela S. (2008). Business Research Methods. $8^{\text {th }}$ Ed. Tata McGraw.

Coyne, Kevin P. (1986). Sustainable competitive advantage - What it is, What it isn't. Business Horizons, 29 (1), 54-61. http://dx.doi.org/10.1016/0007-6813(86)90087-X

D’Aveni, Richard A. (2002). Competitive pressure systems. Mapping and managing multi-market contact. Sloan $\begin{array}{llllll}\text { Management } & \text { Review, } & 44 & \text { (1), } & \text { R9-49. }\end{array}$ http://www.mendeley.com/research/competitive-pressure-systems/

Dess, Gregory G. \& Davis, Peter S. (1984). Porter's (1980) Generic Strategies as Determinants of Strategic Group Membership and Organisational Performance. Academy of Management Journal, 27 (3), 467 - 488.

Eastern Africa Association. (2006). Annual Business Questionnaire Kenya: Commentary \& Findings.

Emory, C William. (1985). Business Research Methods. $3^{\text {rd }}$ Ed. Irwin, Homewood, Illinois.

Furrer, Olivier., Schendel, Dan \& Thomas, Howard. (2002, May). The evolution of strategic management literature: 1980 - 2000. Working paper. University of Nijmegen, Netherlands.

Furrer, Olivier., Alexandre, Maria Teresa., \& Sudharshan D. (2002). The Impact of Resource - Strategy Correspondence on Marketing Performance - Financial Performance Tradeoffs. Working paper, University of Nijmegen, Netherlands.

Gluck, Frederick W., Kaufman, Stephen P. \& Walleck, A Steven. (1980). Strategic management for competitive advantage. Harvard Business Review, $58 \quad$ (4), 154-161. Retrieved from http://hbr.org/1980/07/strategic-management-for-competitive-advantage/ar/1

Govindarajan, Vijay. (1988). A contingency approach to strategy implementation at the business-unit level: Integrating administrative mechanisms with strategy. Academy of Management Journal, 31 (4), 828-853. http://dx.doi.org/10.2307/256341

Gupta, Anil K. (1987). SBU Strategies, corporate-SBU relations, and SBU effectiveness in strategy implementation. Academy of Management Journal, 30 (3), 477-500. http://dx.doi.org/10.2307/256010

Hambrick, Donald C. \& Cannella, Albert A. (1989). Strategy implementation as substance and selling. Academy of Management Executive, 3 (4), 278-285. http://dx.doi.org/10.5465/AME.1989.4277401

Hussey, David. (1996). The Implementation Challenge. John Wiley \& Sons Ltd., West Sussex, England.

Jarillo, Carlos \& Stevenson, Howard H. (1991). Co-operative Strategies -The Payoffs and the Pitfalls. Long Range Planning, 24 (1), 64. http://dx.doi.org/10.1016/0024-6301(91)90025-J

Jennings, Daniel F., \& Seaman, Samwuel L. (1994). High and Low Levels of Organizational Adaptation: An empirical analysis of Strategy, Structure, and Performance. Strategic Management Journal, 15, 459 - 475.

Johnson, Gerry \& Kevan Scholes. (2002). Exploring Corporate Strategy. $\quad 3^{\text {rd }}$ Ed. New York: Prentice Hall.

Kazanjian, Robert K., \& Drazin, Robert. (1987). Implementing internal diversification: Contingency factors for organization design choices. Academy of Management Review, 12 (2), 342-354. http://dx.doi.org/10.2307/258540

Kenya Government. (1988). Economic Management for Renewed Growth (Sessional Paper No. 1 of 1986). Government Press, Nairobi.

Kenya Government. (1997). National Development Plan 1997 - 2001. Government Press. Nairobi.

Kenya Government. (2003). Economic Recovery Strategy For Wealth And Employment Creation 2003 - 2007. Government Press, Nairobi.

Kenya Government. (2006). Private Sector Development Strategy 2006 - 2010. Government Press. Nairobi.

Mintzberg, Henry., Quinn, James Brian \& Ghoshal, Sumantra. (2003). The Strategy Process: Concepts, Contexts, and Cases. Prentice Hall. 
Nielsen, Richard P. (1987). Cooperative Strategy in Marketing. Business Horizon, 30 (4), 61-68. http://dx.doi.org/10.1016/0007-6813(87)90067-X

Pearce ll, John A \& Richard B. Robinson, Jr. (2005). Formulation, Implementation, and Control of Competitive Strategy. Burr Ridge, lll, Irwin.

Poage, James L. Hardball. (2004). Five Killer Strategies for Trouncing the Competition - Response. Harvard Business Review.

Porter, Michael E. (1995). Competitive advantage: Creating \& sustaining superior performance. The free press, New York, USA.

Porter, Michael E. (1998a). Competitive Strategy: Techniques for analysing industries and competitors. The Free Press, New York.

Porter, Michael E. (1998b). Clusters and the new Economics of Competition. Harvard Business Review, 77-90. Retrieved from www.wellbeingcluster.at

Porter, Michael E. (2003). Building the Microeconomic Foundation of Prosperity: Findings from the Business Competitive Index. World Economic Forum 2003 - 2004.

Pricewaterhouse Coopers \& Nation Media Group. (2005). East Africa’s Most Respected Companies Survey 2005. PWC / NMG, Nairobi.

Reed, Richard. \& Buckley, M Ronald. (1991). Strategy in action - Techniques for implementing strategy. In Ken Irons' (Ed) Turning Strategy into action. Pergamon Press.

Ross, E. Joel. (1999). Total Quality Management, $2^{\text {nd }}$ Ed. St. Lucie Press.

Skivington, James K. \& Daft, Richard L. (1991). A Study of Organizational 'Framework' and 'Process' Modalities for the Implementation of Business-Level Strategic Decisions. Journal of Management Studies, Vol. 28 Issue 1, 45-68. http://dx.doi.org/10.1111/j.1467-6486.1991.tb00270.x

Stalk, George. \& Lachenauer, Rob. (2004). Five Killer Strategies for Trouncing the Competition. Harvard Business Review, 63-71.

Tan, J Justin \& Litschert, Robert J. (1994). Environment - Strategy Relationship and its Performance Implications: An Empirical Study of the Chinese Electronic Industry. Strategic Management Journal, 15, 1-20.

United Nations Industrial Development Organization. (1999, October). Capacity Building for Private Sector Development in Africa. Paper presented at the Conference on Industrial Partnerships and Investment in Africa, Dakar, Senegal.

Weiss, Andrew R., \& Birnbaum, Philip H. (1989). Technological infrastructure and the implementation of technological strategies. Management Science, 35 (8), 1014-1026. http://dx.doi.org/10.1287/mnsc.35.8.1014

Wright, Peter., Kroll, Mark., Tu, Howard., \& Helms, Marilyn. (1991). Generic strategies and business performance: An empirical study of the Screw Machine Products Industry. British Journal of Management, 2 (1), 57-65. http://dx.doi.org/10.1111/j.1467-8551.1991.tb00016.x

Zahra, Shaker A., \& Chaples, Sherry S. (1993). Blind spots in competitive analysis. Academy of Management Executive, 7 (2), 7-28. http://dx.doi.org/10.5465/AME.1993.9411302318 
Table1. Implementation levels achieved by cost leaders and differentiators

\begin{tabular}{|c|c|c|c|c|c|c|c|c|c|}
\hline \multirow{3}{*}{ Cost leaders and Differentiators } & \multicolumn{2}{|c|}{$\begin{array}{l}\text { Levene's Test for } \\
\text { Equality of Variances }\end{array}$} & \multicolumn{7}{|c|}{ t-test for Equality of Means } \\
\hline & \multirow{2}{*}{$\begin{array}{c}F \\
\text { Lower } \\
\end{array}$} & \multirow{2}{*}{$\begin{array}{l}\text { Sig. } \\
\text { Upper } \\
\end{array}$} & \multirow{2}{*}{\begin{tabular}{c|}
$t$ \\
\\
Lower \\
\end{tabular}} & \multirow{2}{*}{ Upper } & \multirow{2}{*}{$\begin{array}{c}\text { Sig. } \\
\text { (2-tailed) }\end{array}$} & \multirow{2}{*}{\begin{tabular}{c|}
$\begin{array}{c}\text { Mean } \\
\text { Difference }\end{array}$ \\
\\
Upper \\
\end{tabular}} & \multirow{2}{*}{$\begin{array}{l}\text { Std. Error } \\
\text { Difference } \\
\text { Lower }\end{array}$} & \multicolumn{2}{|c|}{$\begin{array}{l}95 \% \text { Confidence Interval } \\
\text { of the Difference }\end{array}$} \\
\hline & & & & & & & & Upper & Lower \\
\hline $\begin{array}{l}\text { Impl_achiev_Li } \\
\text { Equal variances assumed } \\
\\
\text { Equal variances not assumed }\end{array}$ & .676 & .418 & $\begin{array}{l}-1.350 \\
-1.262\end{array}$ & $\begin{array}{r}28 \\
11.088\end{array}$ & .188 & $\begin{array}{c}-.534 \\
-.534\end{array}$ & .395 & $\begin{array}{l}-1.344 \\
-1.465\end{array}$ & $\begin{array}{l}.276 \\
.397\end{array}$ \\
\hline
\end{tabular}

Table 2. Implementation levels achieved by cost leaders and dual strategists

\begin{tabular}{|c|c|c|c|c|c|c|c|c|c|}
\hline \multirow{3}{*}{ Cost Leaders and Dual Strategists } & \multicolumn{2}{|c|}{$\begin{array}{l}\text { Levene's Test for } \\
\text { Equality of Variances }\end{array}$} & \multicolumn{7}{|c|}{ t-test for Equality of Means } \\
\hline & \multirow{2}{*}{$\begin{array}{c}F \\
\text { Lower } \\
\end{array}$} & \multirow{2}{*}{$\begin{array}{l}\text { Sig. } \\
\text { Upper }\end{array}$} & \multirow{2}{*}{$\begin{array}{c}\mathrm{t} \\
\text { Lower }\end{array}$} & \multirow{2}{*}{$\begin{array}{c}\mathrm{df} \\
\text { Upper }\end{array}$} & \multirow{2}{*}{$\begin{array}{c}\text { Sig. } \\
\text { (2-tailed) } \\
\text { Lower }\end{array}$} & \multirow{2}{*}{$\begin{array}{c}\begin{array}{c}\text { Mean } \\
\text { Difference }\end{array} \\
\text { Upper } \\
\end{array}$} & \multirow{2}{*}{$\begin{array}{c}\text { Std. Error } \\
\text { Difference } \\
\\
\text { Lower } \\
\end{array}$} & \multicolumn{2}{|c|}{$\begin{array}{l}95 \% \text { Confidence Interval } \\
\text { of the Difference }\end{array}$} \\
\hline & & & & & & & & Upper & Lower \\
\hline Impl_achiev_Li Equal variances assumed & 2.323 & .134 & -1.254 & 47 & .216 & .405 & .323 & -1.056 & .245 \\
\hline Equal variances not assumed & & & & 8.584 & .332 & .405 & .395 & -1.305 & .494 \\
\hline
\end{tabular}

Table 3. Implementation levels achieved by differentiators and dual strategist

\begin{tabular}{|c|c|c|c|c|c|c|c|c|c|}
\hline \multirow{3}{*}{ Differentiators and Dual Strategists } & \multicolumn{2}{|c|}{$\begin{array}{l}\text { Levene's Test for } \\
\text { Equality of Variances }\end{array}$} & \multicolumn{7}{|c|}{ t-test for Equality of Means } \\
\hline & \multirow{2}{*}{\begin{tabular}{c|}
$F$ \\
Lower \\
\end{tabular}} & \multirow{2}{*}{$\begin{array}{l}\text { Sig. } \\
\text { Upper }\end{array}$} & \multirow{2}{*}{$\frac{t}{\text { Lower }}$} & \multirow{2}{*}{ Uf } & \multirow{2}{*}{$\begin{array}{c}\begin{array}{c}\text { Sig. } \\
(2-\text { tailed })\end{array} \\
\text { Lower }\end{array}$} & \multirow{2}{*}{$\begin{array}{c}\text { Mean } \\
\text { Difference } \\
\text { Upper } \\
\end{array}$} & \multirow{2}{*}{$\begin{array}{c}\text { Std. Error } \\
\text { Difference } \\
\\
\text { Lower }\end{array}$} & \multicolumn{2}{|c|}{$\begin{array}{c}95 \% \text { Confidence Interval } \\
\text { of the Difference }\end{array}$} \\
\hline & & & & & & & & Upper & Lower \\
\hline $\begin{array}{l}\text { Impl_achiev_Li Equal variances assumed } \\
\\
\text { Equal variances not assumed }\end{array}$ & .715 & .401 & $\begin{array}{l}.581 \\
.554\end{array}$ & $\begin{array}{r}61 \\
37.798\end{array}$ & $\begin{array}{l}.564 \\
.583\end{array}$ & $\begin{array}{l}.129 \\
.129\end{array}$ & .221 & $\begin{array}{l}.314 \\
.341\end{array}$ & .571 \\
\hline
\end{tabular}


Table 4. Multi-regression analysis of implementation level achieved

\begin{tabular}{|c|c|c|c|c|c|c|c|c|c|}
\hline \multirow[t]{2}{*}{ Model } & \multirow{2}{*}{$\mathrm{R}$} & \multirow{2}{*}{$\begin{array}{c}\mathrm{R} \\
\text { Square }\end{array}$} & \multirow{2}{*}{$\begin{array}{l}\text { Adjusted R } \\
\text { Square }\end{array}$} & \multirow{2}{*}{$\begin{array}{l}\text { Std. Error of } \\
\text { the Estimate }\end{array}$} & \multicolumn{5}{|c|}{ Change Statistics } \\
\hline & & & & & $\begin{array}{l}\text { R Square } \\
\text { Change }\end{array}$ & $\begin{array}{c}F \\
\text { Change } \\
\end{array}$ & df1 & df2 & $\begin{array}{l}\text { Sig. F } \\
\text { Change } \\
\end{array}$ \\
\hline 1 & $.604(a)$ & .365 & .356 & .694 & .365 & 39.715 & 1 & 69 & .000 \\
\hline 2 & $.677(b)$ & .458 & .442 & .646 & .093 & 11.686 & 1 & 68 & .001 \\
\hline 3 & $.701(c)$ & -492 & .469 & .631 & .033 & 4.380 & 1 & 67 & .040 \\
\hline 4 & $.722(d)$ & .522 & .493 & .616 & .030 & 4.186 & 1 & 66 & .045 \\
\hline 5 & $.742(e)$ & .551 & .516 & .602 & .029 & 4.179 & 1 & 65 & .045 \\
\hline
\end{tabular}

a Predictors: (Constant), Effectiveness_Ce

b Predictors: (Constant), Effectiveness Ce, CORC C

c Predictors: (Constant), Effectiveness Ce, CORC $-\mathrm{Cr}$, Qty target Qt

d Predictors: (Constant), Effectiveness Ce, CORC Cr, Qty target Qt, Win lose WI

e Predictors: (Constant), Effectiveness_Ce, CORC_Cr, Qty_target_Qt, Win_lose_WI, Envir_change_Ec f Dependent Variable: Impl_achiev_Li

\begin{tabular}{|c|c|c|c|c|c|c|}
\hline \multicolumn{2}{|c|}{ Model } & $\begin{array}{l}\text { Sum of } \\
\text { Squares }\end{array}$ & $\mathrm{df}$ & Mean Square & $\mathrm{F}$ & Sig. \\
\hline \multirow[t]{3}{*}{1} & Regression & 19.140 & 1 & 19.140 & 39.715 & $.000(a)$ \\
\hline & Residual & 33.254 & 69 & .482 & & \\
\hline & Total & 52.394 & 70 & & & \\
\hline \multirow[t]{3}{*}{2} & Regression & 24.017 & 2 & 12.009 & 28.776 & $.000(b)$ \\
\hline & Residual & 28.377 & 68 & -417 & & \\
\hline & Total & 52.394 & 70 & & & \\
\hline \multirow[t]{3}{*}{3} & Regression & 25.759 & 3 & 8.586 & 21.598 & $.000(c)$ \\
\hline & Residual & 26.636 & 67 & .398 & & \\
\hline & Total & 52.394 & 70 & & & \\
\hline \multirow[t]{3}{*}{4} & Regression & 27.347 & 4 & 6.837 & 18.015 & $.000(d)$ \\
\hline & Residual & 25.047 & 66 & .380 & & \\
\hline & Total & 52.394 & 70 & & & \\
\hline \multirow[t]{3}{*}{5} & Regression & 28.860 & 5 & 5.772 & 15.942 & $.000(e)$ \\
\hline & Residual & 23.534 & 65 & .362 & & \\
\hline & Total & 52.394 & 70 & & & \\
\hline
\end{tabular}

a Predictors: (Constant), Effectiveness_Ce

b Predictors: (Constant), Effectiveness Ce, CORC $\mathrm{Gr}$

c Predictors: (Constant), Effectiveness_Ge, GORG_Gr, Qty_target_Qt

d Predictors: (Constant), Effectiveness_Ce, CORC_Cr, Qty_target_Qt, Win_lose_WI

^ Predictors: (Constant), Effectiveness_Ce, CORC_Cr, Qty_target_Qt, Win_lose_WI, Envir_change_Ec

f Dependent Variable: Impl achiev Li

\begin{tabular}{|c|c|c|c|c|c|c|c|c|}
\hline \multirow{2}{*}{\multicolumn{2}{|c|}{ Model }} & \multicolumn{2}{|c|}{$\begin{array}{l}\text { Unstandardized } \\
\text { Coefficients }\end{array}$} & \multirow{2}{*}{$\begin{array}{c}\text { Standardized } \\
\text { Coefficients } \\
\text { Beta } \\
\end{array}$} & \multirow[b]{2}{*}{$t$} & \multirow[b]{2}{*}{ Sig. } & \multicolumn{2}{|c|}{$\begin{array}{l}\text { Collinearity } \\
\text { Statistics }\end{array}$} \\
\hline & & B & $\begin{array}{l}\text { Std. } \\
\text { Error }\end{array}$ & & & & Tolerance & VIF \\
\hline \multirow[t]{2}{*}{1} & (Constant) & 1.599 & .355 & & 4.505 & .000 & & \\
\hline & Effectiveness_Ce & .560 & .089 & .604 & 6.302 & .000 & 1.000 & 1.000 \\
\hline \multirow[t]{3}{*}{2} & (Constant) & 1.067 & .365 & & 2.921 & .005 & & \\
\hline & Effectiveness_Ce & .383 & .097 & .414 & 3.936 & .000 & .720 & 1.389 \\
\hline & GORC_Cr & .343 & -100 & .360 & 3.419 & -001 & .720 & 1.389 \\
\hline \multirow[t]{4}{*}{3} & (Constānt) & .746 & .388 & & 1.924 & .059 & & \\
\hline & Effectiveness_Ce & .334 & .098 & .361 & 3.413 & .001 & .678 & 1.474 \\
\hline & CORC_Cr & .306 & .100 & .321 & 3.074 & .003 & .697 & 1.435 \\
\hline & Qty_target_Qt & .163 & .078 & .199 & 2.093 & .040 & .836 & 1.196 \\
\hline \multirow[t]{4}{*}{4} & (Constant) & .320 & .432 & & .741 & .461 & & \\
\hline & $\begin{array}{l}\text { Effectiveness_Ce } \\
\text { CORC Cr }\end{array}$ & $\begin{array}{l}.336 \\
.331\end{array}$ & $\begin{array}{l}.096 \\
.098\end{array}$ & $\begin{array}{l}.363 \\
.347\end{array}$ & $\begin{array}{l}3.513 \\
3.380\end{array}$ & $\begin{array}{l}.001 \\
.001\end{array}$ & $\begin{array}{l}.678 \\
.686\end{array}$ & $\begin{array}{l}1.474 \\
1.458\end{array}$ \\
\hline & Qty_target_Qt & .174 & .076 & .213 & 2.282 & .026 & .832 & 1.202 \\
\hline & Win_lose_WI & .112 & .055 & .178 & 2.046 & .045 & .961 & 1.040 \\
\hline \multirow[t]{6}{*}{5} & (Constant) & -.147 & .480 & & -.306 & .760 & & \\
\hline & Effectiveness_Ce & .346 & .094 & .374 & 3.699 & .000 & .676 & 1.478 \\
\hline & GORC_Cr & .353 & .096 & .370 & 3.660 & .001 & .678 & 1.475 \\
\hline & Qty_target_Qt & .178 & .074 & .219 & 2.398 & .019 & .831 & 1.203 \\
\hline & Win_lose_WI & .113 & .053 & .179 & 2.108 & .039 & .961 & 1.040 \\
\hline & Envir_change_Ec & .131 & .064 & .173 & 2.044 & .045 & .966 & 1.035 \\
\hline
\end{tabular}


Table 5. Cost leaders and differentiators' use of implementation armaments

\begin{tabular}{|c|c|c|c|c|c|c|c|c|c|c|}
\hline & & \multicolumn{2}{|c|}{$\begin{array}{l}\text { Levene's Test for } \\
\text { Equality of Variances }\end{array}$} & \multicolumn{7}{|c|}{ t-test for Equality of Means } \\
\hline & & \multirow{2}{*}{$\begin{array}{c}F \\
\text { Lower }\end{array}$} & \multirow{2}{*}{$\frac{\text { Sig. }}{\text { Upper }}$} & \multirow{2}{*}{$\frac{t}{\text { Lower }}$} & \multirow{2}{*}{$\begin{array}{c}\text { df } \\
\text { Upper }\end{array}$} & \multirow{2}{*}{$\begin{array}{c}\begin{array}{c}\text { Sig. } \\
\text { (2-tailed) }\end{array} \\
\text { Lower }\end{array}$} & \multirow{2}{*}{$\begin{array}{c}\begin{array}{c}\text { Mean } \\
\text { Difference }\end{array} \\
\text { Upper }\end{array}$} & \multirow{2}{*}{$\begin{array}{c}\text { Std. Error } \\
\text { Difference }\end{array}$} & \multicolumn{2}{|c|}{$\begin{array}{l}95 \% \text { Confidence Interval } \\
\text { of the Difference }\end{array}$} \\
\hline & & & & & & & & & Upper & Lower \\
\hline \multirow[t]{2}{*}{ Leadership } & Equal variances assumed & .024 & .879 & -1.621 & 28 & .116 & -.591 & .364 & -1.337 & .156 \\
\hline & Equal variances not assumed & & & -1.782 & 15.130 & .095 & -.591 & .332 & -1.297 & .115 \\
\hline \multirow[t]{2}{*}{ Communication } & Equal variances assumed & .675 & .418 & -3.314 & 28 & .003 & -.784 & .237 & -1.269 & -.300 \\
\hline & Equal variances not assumed & & & -2.760 & 9.436 & .021 & -.784 & .284 & -1.422 & -.146 \\
\hline \multirow[t]{2}{*}{ Training } & Equal variances assumed & .259 & .614 & -.623 & 28 & .538 & -.227 & .365 & -.975 & .520 \\
\hline & Equal variances not assumed & & & -.604 & 11.802 & .557 & -.227 & .376 & -1.048 & .594 \\
\hline \multirow[t]{2}{*}{ Consensus } & Equal variances assumed & .634 & .433 & -1.883 & 28 & .070 & -.670 & .356 & -1.400 & .059 \\
\hline & Equal variances not assumed & & & -1.810 & 11.617 & .096 & -.670 & .371 & -1.481 & .140 \\
\hline \multirow[t]{2}{*}{ Culture } & Equal variances assumed & .000 & .998 & -1.946 & 28 & .062 & -.602 & .310 & -1.236 & .032 \\
\hline & Equal variances not assumed & & & -1.955 & 12.582 & .073 & -.602 & .308 & -1.270 & .065 \\
\hline \multirow[t]{2}{*}{$\mathrm{CORC}-\mathrm{Cr}$} & Equal variances assumed & .625 & .436 & -2.256 & 28 & .032 & -.841 & .373 & -1.604 & -.077 \\
\hline & Equal variances not assumed & & & -2.604 & 16.968 & .019 & -.841 & .323 & -1.522 & -.159 \\
\hline \multirow[t]{2}{*}{ Structure } & Equal variances assumed & .065 & .801 & -3.210 & 28 & .003 & -1.239 & .386 & -2.029 & -.448 \\
\hline & Equal variances not assumed & & & -3.251 & 12.773 & .006 & -1.239 & .381 & -2.063 & -.414 \\
\hline \multirow[t]{2}{*}{ Resources } & Equal variances assumed & 1.290 & .266 & -2.568 & 28 & .016 & -.659 & .257 & -1.185 & -.133 \\
\hline & Equal variances not assumed & & & -1.990 & 8.697 & .079 & -.659 & .331 & -1.412 & .094 \\
\hline \multirow[t]{2}{*}{ Rewards } & Equal variances assumed & .172 & .682 & -1.163 & 28 & .255 & -.557 & .479 & -1.537 & .424 \\
\hline & Equal variances not assumed & & & -1.280 & 15.168 & .220 & -.557 & .435 & -1.483 & .370 \\
\hline \multirow[t]{2}{*}{ Win-lose } & Equal variances assumed & .065 & .801 & .125 & 28 & .901 & .068 & .545 & -1.048 & 1.184 \\
\hline & Equal variances not assumed & & & .115 & 10.871 & .910 & .068 & .591 & -1.234 & 1.370 \\
\hline \multirow[t]{2}{*}{ Win-win } & Equal variances assumed & .374 & .546 & .280 & 28 & .782 & .136 & .488 & -.863 & 1.136 \\
\hline & Equal variances not assumed & & & .297 & 14.105 & .770 & .136 & .458 & -.846 & 1.119 \\
\hline
\end{tabular}

Table 6. Implementation armaments by low cost leaders and dual strategists

\begin{tabular}{|c|c|c|c|c|c|c|c|c|c|c|}
\hline & & \multicolumn{2}{|c|}{$\begin{array}{l}\text { Levene's Test for } \\
\text { Equality of Variances }\end{array}$} & \multicolumn{7}{|c|}{ t-test for Equality of Means } \\
\hline & & \multirow{2}{*}{$\begin{array}{c}\mathrm{F} \\
\text { Lower } \\
\end{array}$} & \multirow{2}{*}{$\begin{array}{c}\text { Sig. } \\
\text { Upper }\end{array}$} & \multirow{2}{*}{$\begin{array}{c}\mathrm{t} \\
\text { Lower }\end{array}$} & \multirow{2}{*}{$\begin{array}{c}\text { df } \\
\text { Upper }\end{array}$} & \multirow{2}{*}{$\begin{array}{c}\begin{array}{c}\text { Sig. } \\
\text { (2-tailed) }\end{array} \\
\text { Lower } \\
\end{array}$} & \multirow{2}{*}{$\begin{array}{c}\text { Mean } \\
\text { Difference }\end{array}$} & \multirow{2}{*}{$\begin{array}{c}\text { Std. Error } \\
\text { Difference } \\
\\
\text { Lower }\end{array}$} & \multicolumn{2}{|c|}{$\begin{array}{l}95 \% \text { Confidence Interval } \\
\text { of the Difference }\end{array}$} \\
\hline & & & & & & & & & Upper & Lower \\
\hline \multirow[t]{2}{*}{ Leadership } & Equal variances assumed & .280 & .599 & -1.521 & 47 & .135 & -.500 & .329 & -1.161 & .161 \\
\hline & Equal variances not assumed & & & -1.669 & 10.919 & .123 & -.500 & .300 & -1.160 & .160 \\
\hline \multirow[t]{2}{*}{ Communication } & Equal variances assumed & .008 & .929 & -1.610 & 47 & .114 & -.521 & .324 & -1.173 & .130 \\
\hline & Equal variances not assumed & & & -1.768 & 10.928 & .105 & -.521 & .295 & -1.171 & .128 \\
\hline \multirow[t]{2}{*}{ Training } & Equal variances assumed & .190 & .665 & -.973 & 47 & .336 & -.293 & .301 & -.898 & .313 \\
\hline & Equal variances not assumed & & & -.842 & 8.881 & .422 & -.293 & .348 & -1.081 & .495 \\
\hline \multirow[t]{2}{*}{ Consensus } & Equal variances assumed & .072 & .789 & -.535 & 47 & .595 & -.186 & .347 & -.885 & .513 \\
\hline & Equal variances not assumed & & & -.527 & 9.796 & .610 & -.186 & .353 & -.974 & .602 \\
\hline \multirow[t]{2}{*}{ Culture } & Equal variances assumed & .013 & .911 & -1.391 & 47 & .171 & -.448 & .322 & -1.096 & .200 \\
\hline & Equal variances not assumed & & & -1.522 & 10.878 & .157 & -.448 & .295 & -1.097 & .201 \\
\hline \multirow[t]{2}{*}{$\mathrm{CORC} \cdot \mathrm{Cr}$} & Equal variances assumed & .091 & .764 & -2.908 & 47 & .006 & -.933 & .321 & -1.578 & -.288 \\
\hline & Equal variances not assumed & & & -3.296 & 11.342 & .007 & -.933 & .283 & -1.554 & -.312 \\
\hline \multirow[t]{2}{*}{ Structure } & Equal variances assumed & .332 & .567 & -4.754 & 47 & .000 & -1.570 & .330 & -2.235 & -.906 \\
\hline & Equal variances not assumed & & & -4.491 & 9.460 & .001 & -1.570 & .350 & -2.355 & -.785 \\
\hline \multirow[t]{2}{*}{ Resources } & Equal variances assumed & 1.042 & .313 & -1.163 & 47 & .251 & -.323 & .278 & -.882 & .236 \\
\hline & Equal variances not assumed & & & -.976 & 8.707 & .355 & -.323 & .331 & -1.076 & .430 \\
\hline \multirow[t]{2}{*}{ Rewards } & Equal variances assumed & .172 & .681 & -1.356 & 47 & .182 & -.509 & .376 & -1.265 & .246 \\
\hline & Equal variances not assumed & & & -1.334 & 9.792 & .212 & -.509 & .382 & -1.362 & .344 \\
\hline \multirow[t]{2}{*}{ Win-lose } & Equal variances assumed & .464 & .499 & -.978 & 47 & .333 & -.530 & .542 & -1.621 & .560 \\
\hline & Equal variances not assumed & & & -.932 & 9.529 & .374 & -.530 & .569 & -1.807 & .746 \\
\hline \multirow[t]{2}{*}{ Win-win } & Equal variances assumed & .004 & .952 & -.030 & 47 & .976 & -.012 & .408 & -.832 & .808 \\
\hline & Equal variances not assumed & & & -.030 & 9.832 & .977 & -.012 & .412 & -.933 & .908 \\
\hline
\end{tabular}


Table 7. Differentiators and dual strategists' use of soft and hard armaments

\begin{tabular}{|c|c|c|c|c|c|c|c|c|c|c|}
\hline & & \multicolumn{2}{|c|}{$\begin{array}{l}\text { Levene's Test for } \\
\text { Equality of Variances }\end{array}$} & \multicolumn{7}{|c|}{ t-test for Equality of Means } \\
\hline & & \multirow{2}{*}{$\begin{array}{c}F \\
\text { Lower }\end{array}$} & \multirow{2}{*}{$\begin{array}{l}\text { Sig. } \\
\text { Upper }\end{array}$} & \multirow{2}{*}{$\frac{t}{\text { Lower }}$} & \multirow{2}{*}{$\begin{array}{c}\text { df } \\
\text { Upper }\end{array}$} & \multirow{2}{*}{$\begin{array}{c}\begin{array}{c}\text { Sig. } \\
\text { (2-tailed) }\end{array} \\
\text { Lower }\end{array}$} & \multirow{2}{*}{$\begin{array}{c}\begin{array}{c}\text { Mean } \\
\text { Difference }\end{array} \\
\text { Upper }\end{array}$} & \multirow{2}{*}{$\begin{array}{c}\text { Std. Error } \\
\text { Difference }\end{array}$} & \multicolumn{2}{|c|}{$\begin{array}{l}95 \% \text { Confidence Interval } \\
\text { of the Difference }\end{array}$} \\
\hline & & & & & & & & & Upper & Lower \\
\hline \multirow[t]{2}{*}{ Leadership } & Equal variances assumed & .923 & .341 & .389 & 61 & .699 & .091 & .234 & -.377 & .559 \\
\hline & Equal variances not assumed & & & .381 & 40.823 & .705 & .091 & .238 & -.391 & .573 \\
\hline \multirow[t]{2}{*}{ Training } & Equal variances assumed & .118 & .732 & -.312 & 61 & .756 & -.065 & .210 & -.484 & .354 \\
\hline & Equal variances not assumed & & & -298 & 37.944 & .767 & -.065 & .219 & -.509 & .378 \\
\hline \multirow[t]{2}{*}{ Consensus } & Equal variances assumed & .776 & .382 & 2.087 & 61 & .041 & .484 & .232 & .020 & .949 \\
\hline & Equal variances not assumed & & & 2.126 & 45.365 & .039 & .484 & .228 & .026 & .943 \\
\hline Culture & Equal variances assumed & .030 & .864 & .714 & 61 & .478 & .154 & .216 & -.277 & .585 \\
\hline Structure & Equal variances not assumed & & & -1.381 & 39.179 & .175 & -.331 & .240 & -.817 & .154 \\
\hline \multirow[t]{2}{*}{ Resources } & Equal variances assumed & .421 & .519 & 2.022 & 61 & .048 & .336 & .166 & .004 & .668 \\
\hline & Equal variances not assumed & & & 2.217 & 54.993 & .031 & .336 & .152 & .032 & .640 \\
\hline \multirow[t]{2}{*}{ Rewards } & Equal variances assumed & 1.424 & .237 & .170 & 61 & .865 & .048 & .280 & -.511 & .607 \\
\hline & Equal variances not assumed & & & .159 & 35.690 & .874 & .048 & .299 & -.559 & .655 \\
\hline \multirow[t]{2}{*}{ WinLose } & Equal variances assumed & 2.340 & .131 & -1.685 & 61 & .097 & -.599 & .355 & -1.309 & .112 \\
\hline & Equal variances not assumed & & & -1.736 & 46.858 & .089 & -.599 & .345 & -1.293 & .095 \\
\hline \multirow[t]{2}{*}{ WinWin } & Equal variances assumed & 1.069 & .305 & -.506 & 61 & .615 & -.149 & .294 & -.736 & .439 \\
\hline & Equal variances not assumed & & & -.484 & 38.005 & .631 & -.149 & .307 & -.770 & .473 \\
\hline
\end{tabular}

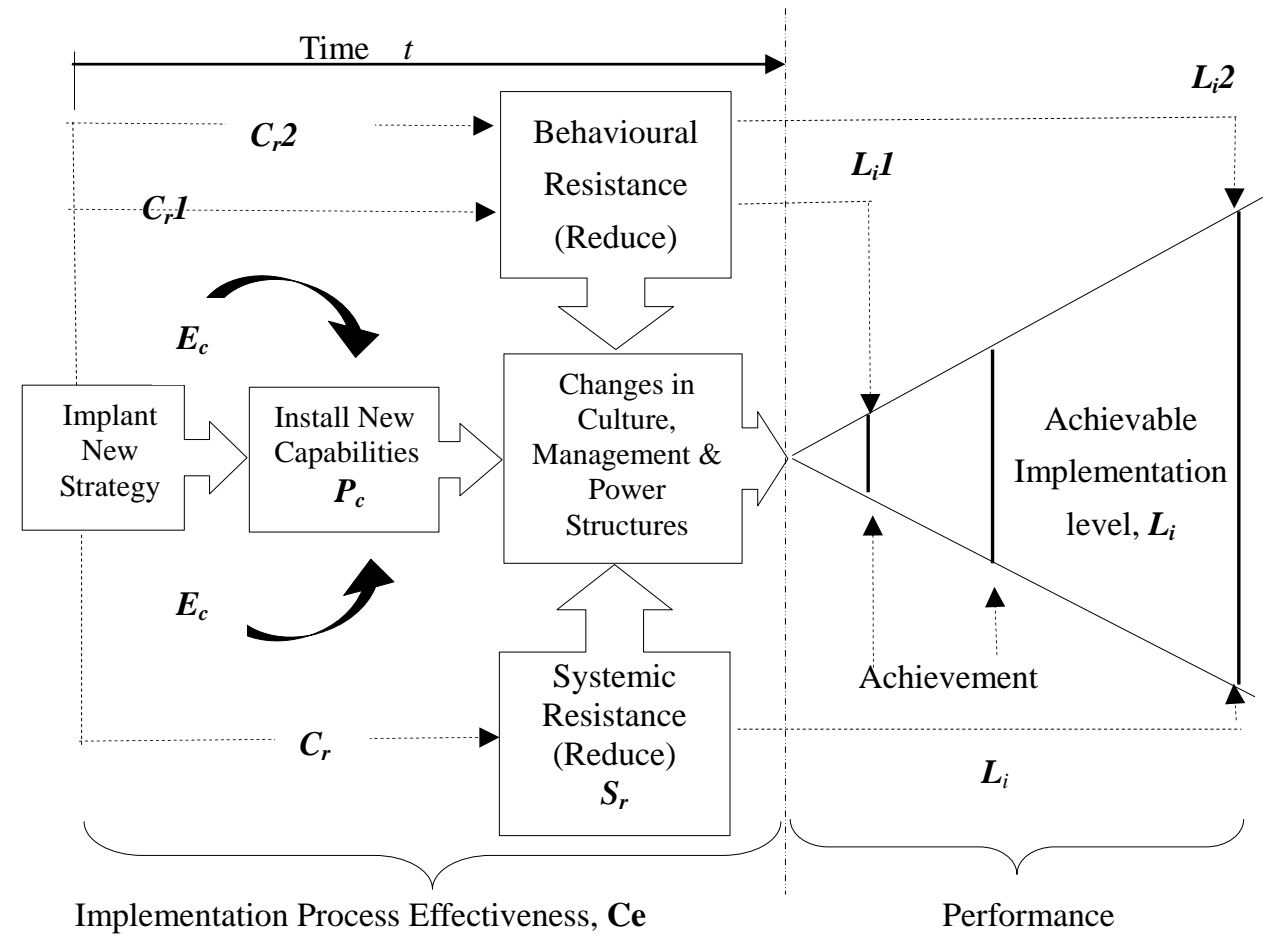

Figure 1. Strategy Implementation Concept 